\title{
MEDIAN RHOMBOID GLOSSITIS: A PECULIAR TONGUE PATHOLOGY, REPORT OF A CASE AND REVIEW OF LITERATURE
}

\author{
${ }^{1}$ Daud Mirza, ${ }^{2}$ Ghazal Raza, ${ }^{3}$ Zubair Ahmed Abassi \\ 1, 2 Department of Oral Pathology. Bahria University Medical\& Dental College, Karachi, Pakistan. \\ ${ }^{3}$ Department of Oral Maxillofacial Surgery, Bahria University Medical \& Dental College, Karachi, Pakistan.
}

*Corresponding Author Email: dr.daud mirza@hotmail.com

\begin{abstract}
Median rhomboid glossitis (MRG) is unique tongue pathology of uncertain etiology, typically located around the midline of dorsal surface of tongue. Clinically it appears as reddish, depapillated area usually rhomboid in shape. Due its asymptomatic nature it is considered as a benign condition which in most of the cases generally discovered on routine oral examination. In this paper, we present a first case on median rhomboid glossitis which consulted for routine dental checkup. To our knowledge MRG has never been reported in Pakistani literature. We present a case report literature review, discussion including insight regarding aetiology, clinical presentation and management of the condition.
\end{abstract}

\section{KEY WORDS}

Candidiasis, Pakistan, Tongue, glossitis, Median rhomboid

\section{INTRODUCTION:}

Median rhomboid glossitis (MRG) is a benign uncommon usually asymptomatic condition of tongue superimposed by secondary infection usually by candida. It is characterized by central papillary atrophy of dorsal surface of tongue particularly anterior to the circumvallate papillae. ${ }^{1}$ It predominantly affects males ${ }^{2}$ while few studies showed female preponderance ${ }^{3,4}$ The etiopathogeness of MRG is uncertain but it was once attributed to an embryologic fault caused by failure of tuberculum impar to unite completely with lateral processes of the tongue which results in area of smooth, erythematous oral mucosa on posterior dorsal surface of tongue with scarcity of papillae. ${ }^{5}$ Most of the researchers nowadays do not endorse this theory. A recent development revealed that posterior dorsal surface of tongue is the main reservoir of candidal microorganisms in oral cavity. However, there are some local factors which include trauma or surface variation in the anatomy which may allow candidal hyphae to proliferate leading to the development of $\mathrm{MRG}^{6,5}$ Studies has shown diverse predisposing factors associated with median rhomboid glossitis such as denture wearing, smoking, diabetes mellitus ${ }^{7,8}$ The most widely accepted theory is that candidal infections play an important role in etiology. ${ }^{9}$

The aim of this case report is to determine the clinical presentation, etiological factors and its effects on tongue and associated oral structures.

Case Report: 
A 38-old female visited to Out Patient department of Bahria University Dental Hospital for routine dental checkup. Clinical examination of mouth revealed a well demarcated rhomboid area of depapillation on the dorsal surface of tongue just anterior to circumvallate papillae. The surface was smooth and raised, the palatal mucosa was normal. On further inquiry, there were no any associated complaints.

She noticed a red patch on her tongue six months ago, which was asymptomatic. She did not seek any medical advice. Her medical history was unremarkable. A working clinical diagnosis of 'median rhomboid glossitis' was made.

Due to its asymptomatic nature, no treatment was advised. She was reassured and regular monitoring recommended after three to six months.

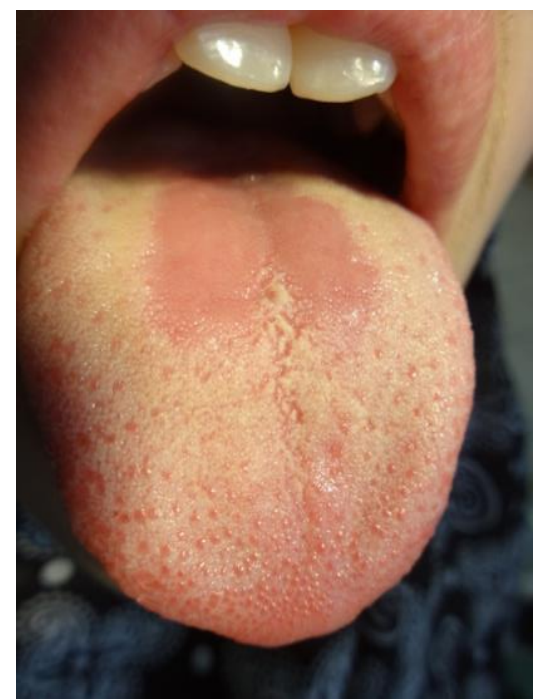

Figure 1: A 38 old female patient showing MRG on the dorsal surface of tongue

\section{DISCUSSION:}

There are variety of tongue lesions which are health concern for both clinicians and patients. Therefore, it is mandatory for the dentist to become aware of these conditions and their etiology, clinical features, diagnosis, and management.

MRG is perceived as manifestation of chronic candidiasis and it was described first by Brocq in
1914. ${ }^{1}$ The prevalence of MRG varies around the world. Yarom conducted study among adult Israeli Jewish population showed the prevalence rate was $2.4 \% .{ }^{10}$ while an Iranian study showed $6.43 \%$ in diabetic patients. ${ }^{11}$ The prevalence of MRG among Jordanian and Malaysian subjects was found to be $0.5 \%{ }^{12}$ and $0.2 \%$ respectively. ${ }^{13}$ Espinoza study in Brazilian aging Chileans revealed $0.9 \%$ prevalence of MRG. ${ }^{14}$ So far, no data is published in Pakistan regarding the prevalence of MRG at national level. Literatures have shown that MRG is very rare among children, but Robert's study on Minnesota school children demonstrated $0.14 \%$ prevalence. MRG is usually asymptomatic but in some situation, may cause burning sensation which is associated with food condiments which may warrant the patient to seek medical assistance. ${ }^{15}$

The exact etiology of MRG is controversial. Several factors have been proposed as possible causes such as denture wearing, smoking, diabetes mellitus, use of corticosteroids sprays or inhalers and human immunodeficiency virus (HIV). ${ }^{16}$ Most of researchers have now agreed that MRG is a variant of the oral lesion associated with candida infections. Ghabanchi conducted study on Iranian diabetics (Type 1 and II) patients showed increased prevalence of MRG than that of control group. ${ }^{11}$ Deshpande conducted a study showing a unique case of MRG infested with heavy colonies of actinomycosis in a sixty-year-old man. ${ }^{17}$

\section{CONCLUSION:}

Previous researchers have shown a strong association of systemic diseases and presence of MRG. The author is of opinion that other local and 
systemic risk factors must be explored to identify those factors and prevent the onset of disease.

\section{REFERENCES :}

1. Lago-Méndez L, Blanco-Carrión A, Diniz-Freitas $M$, Gánda-ra-Vila P, García-García A, Gándara-Rey JM. Rhomboid glossitis in atypical location: case report and differential diagnosis. Med Oral Patol Oral Cir Bucal 2005; 10:123-12

2. Rogers RS, 3rd, Bruce AJ. The tongue in clinical diagnosis. J Eur Acad Dermatol Venereol. 2004; 18:254-259.

3. Avcu N, Kanli A. The prevalence of tongue lesions in 5150 Turkish dental outpatients. Oral Dis. 2003; 9:188-195.

4. Wright BA. Median rhomboid glossitis: not a misnomer. Review of the literature and histologic study of twenty-eight cases. Oral Surg Oral Med Oral Pathol. 1978; 46:806-814.

5. Mustafa Goregen, Ozkan Miloglu, Mustafa Cemil Buyukkurt, Fatma Caglayan, Ayse Esin Aktas. Median Rhomboid Glossitis: A Clinical and Microbiological Study. Eur J Dent. 2011 Oct; 5(4): 367-372.

6. Prashanth Panta, Sridhar Reddy Erugula. Median rhomboid glossitis-developmental or candidal? Pan Afr Med J. 2015; 21: 221.

7. Van der Wal N, van der Kwast WA, van der Waal I. Median rhomboid glossitis: A follow-up study of 16 patients. J Oral Med. 1986; 41:117-120.

8. Soysa NS, Ellepola AN. The impact of cigarette/tobacco smoking on oral candidiasis: an overview. Oral Dis. 2005; 11:268-273.]
9. Terai $\mathrm{H}$, Shimahara M. Partial atrophic tongue other than median rhomboid glossitis. Clin Exp Dermatol. 2007; 32:381-384.

10. Yarom N. - Cantony U. - Gorsky M. Prevalence of Fissured Tongue, Geographic Tongue, and Median Rhomboid Glossitis among Israeli Adults of Different Ethnic Origins. Dermatology 2004; 209:88-94.

11. Ghabanchi J, Andisheh Tadbir A, Darafshi R, Sadegholvad M. The prevalence of median rhomboid glossitis in diabetic patients: a casecontrol study. Iran Red Crescent Med J. 2011 Jul;13(7):503-6.

12. Darwazeh AM, Almelaih AA. Tongue lesions in a Jordanian population. Prevalence, symptoms, subject's knowledge, and treatment provided. Med Oral Patol Oral Cir Bucal. 2011 Sep 1;16(6):e745-9

13. Koay $\mathrm{CL}$, Lim JA, Siar $\mathrm{CH}$. The prevalence of tongue lesions in Malaysian dental outpatients from the Klang Valley area. Oral Dis. 2011 Mar;17(2):210-6.

14. Espinoza I, Rojas R, Aranda W, Gamonal J. Prevalence of oral mucosal lesions in elderly people in Santiago, Chile. J Oral Pathol Med. 2003 Nov;32(10):571-5.

15. Leite RMS, Leite, AAC, Friedman H, Friedman I. Median rhomboid glossitis associated with esophagic candidiasis: a possible etiologic relation with candida albicans. An. Bras. Dermatol. 2002, vol.77, n.5 [cited 2016-10-25], pp.579-583

16. Samaranayake LP, Keung Leung W, Jin L. Oral mucosal fungal infections. Periodontol 2000. 2009;49:39-59.

17. Deshpande RB, Bharucha MA. Median rhomboid glossitis: secondary to colonisation of the tongue by Actinomyces (a case report). J Postgrad Med. 1991 Oct;37(4):238-40. 